\title{
Shinju Dalam Cerpen Sonezaki Shinju Dan Cerpen Shinju Ten No Amijima Karya Chikamatsu Monzaemon
}

\author{
Putu Mia Sintya Dewi $^{1^{*}}$, I Made Sendra ${ }^{2}$, Ni Luh Putu Ari Sulatri ${ }^{3}$ \\ ${ }^{[1,3]}$ Program Studi Sastra Jepang Fakultas Ilmu Budaya \\ ${ }^{[2]}$ Program Srtudi Industri Perjalanan Wisata Fakultas Pariwisata \\ 1'[miasintya31@gmail.com], [sendramade65@gmail.com], ${ }^{3}$ [ari_sulatri@unud.ac.id] \\ Denpasar, Bali, Indonesia \\ *Corresponding Author
}

\begin{abstract}
The title of this research is "Shinju in Sonezaki Shinju and Shinju Ten no Amijima, Short Stories by Chikamatsu Monzaemon". This research aims to examine the background factors of shinju and the author's view of shinju in the Sonezaki Shinju short story and Chikamatsu Monzaemon's Shinju Ten no Amijima short story. The method used in this research is a descriptive analysis method by Ratna (2015). The theory used in this research are the sociological theory of literature proposed by Wellek \& Werren (1990), the author's worldview theory proposed by Goldmann in Faruk (2010) and suicide theory proposed by Emile Durkheim (1897). Based on the results of the analysis found three factors underlying the occurrence of the shinju phenomenon in the Sonezaki Shinju short story, such as 1) shinju as a form of rejection of custom marriage, 2) shinju as a way out of conflict between on, giri, and ninjo, and 3) shinju is a form of proof of love, while in Chikamatsu Monzaemon's Shinju Ten no Amijima short story there are three factors underlying the shinju phenomenon, such as 1) shinju as a form of implementation of giri, 2) shinju as a form of shame, and 3) shinju as a form of proof of love. From these factors there are also three authors' views about shinju itself, such as 1)shinju restores self-esteem, 2) shinju to remove shame, and 3) shinju as a union of love.
\end{abstract}

Keywords: shinju, omiai kekkon, on, giri, ninjo

\begin{abstract}
Abstrak
Penelitian ini bertujuan untuk mengkaji faktor yang melatarbelakangi shinju serta pandangan pengarang mengenai shinju dalam cerpen Sonezaki Shinju dan cerpen Shinju Ten no Amijima karya Chikamatsu Monzaemon.Metode yang digunakan dalam penelitian ini adalah metode desktriptif analisis oleh Ratna (2015). Teori yang digunakan dalam penelitian ini adalah teori sosiologi sastra yang dikemukakan oleh Wellek\&Werren (1990), teori pandangan dunia pengarang yang dikemukakan oleh Goldmann dalam Faruk (2010) dan teori bunuh diri yang dikemukakan oleh Emile Durkheim(1897). Berdasarkan hasil analisis ditemukan tiga faktor yang melatarbelakangi terjadinya fenomena shinju dalam cerpen Sonezaki Shinju yaitu 1) shinju sebagai bentuk penolakan atas adat perjodohan, 2) shinju sebagai jalan keluar dari konflik on,giri, dan ninjo, dan 3) shinju sebagai bentuk pembuktian cinta, sedangkan pada cerpen Shinju Ten no Amijima karya Chikamatsu Monzaemon terdapat tiga faktor yang melatarbelakangi terjadinya fenomena shinju yaitu 1)shinju sebagai bentuk pelaksanaan giri, 2)shinjusebagai bentuk rasa malu dan 3)shinju sebagai bentuk pembuktian cinta. Dari faktor-faktor tersebut ditemukan pula tiga pandangan pengarang mengenai shinju itu sendiri,
\end{abstract}

\begin{tabular}{lll}
\hline Info Article & & \\
\hline Received & $:$ & $12^{\text {th }}$ August 2019 \\
Accepted & $:$ & $11^{\text {th }}$ May 2020 \\
Publised & $:$ & $31^{\text {st }}$ May 2020
\end{tabular}


yaitu 1)shinju bertujuan untukmemulihkan harga diri, 2)shinju bertujuan untuk menghapus rasa malu, dan 3)shinju sebagai penyatuan cinta.

Kata Kunci : shinju, omiai kekkon, on, giri, ninjo

\section{PENDAHULUAN}

Shinju merupakan fenomena bunuh diri yang dilakukan oleh dua orang atau lebih yang dalam bahasa Inggris disebut double suicide. Di Jepang istilah shinju bukanlah merupakan sebuah hal yang baru. Mudahnya orang Jepang yang terluka oleh kegagalan, penolakan, dan penghinaan cenderung membuat mereka melukai dirinya sendiri (Eisenstadt, 1996:325).

Pada saat zaman Edo, shinjumerujuk pada bunuh diri yang dilakukan oleh sepasang kekasih karena hubungan cinta mereka tidak direstui. Hal tersebut diakibatkan oleh sistem stratifikasi sosial yang melarang perkawinan berbeda golongan. Maraknya bunuh diri di Jepang kala itu membuat pengarang karya sastra menciptakan beberapa karya yang bertemakan shinju. Dua diantaranya adalah cerpen karya Chikamatsu Monzaemon yang berjudul Sonezaki Shinju dan Shinju Ten no Amijima.

Sonezaki Shinju adalah cerpen yang bercerita tentang persitiwa bunuh diri yang dilakukan oleh sepasang kekasih. Cerpen ini bercerita tentang rencana pernikahan atas dasar perjodohan yang dilakukan oleh tokoh paman dari Tokubei.Paman Tokubei ingin menjodohkan keponakan istrinya dengan Tokubei, namun Tokubei menolak perjodohan tersebut, karena Tokubei lebih mencintai kekasihnya yaitu Ohatsu. Kisah cinta antara Tokubei dan Ohatsu mengalami banyak ujian, yang menyebabkan cinta mereka tidak sampai ke jenjang pernikahan. Oleh karena itu, mereka melakukan shinju di hutan Sonezaki. Keputusan Tokubei dan Ohatsu untuk melakukan shinju dilatarbelakangi oleh ketidakberterimaan mereka terhadap adat perjodohan (miai kekkon) di masyarakat.

Cerpen kedua yang mengangkat kisah mengenai shinju adalah cerpen Shinju Ten no Amijima. Cerpen ini menceritakan tentang seorang tokoh yang bernama Jihei yang bekerja di toko kertas. Jihei memiliki seorang istri yang bernama Osan. Osan memiliki seorang sahabat yang bernama Koharu. Koharu merupakan seorang pelacur kelas atas, ia selalu membantu Osan jika Osan mengalami kesusahan. Akan tetapi tanpa disangka-sangka Jihei yang merupakan suami dari Osan ternyata berselingkuh dengan Koharu. Perselingkuhan itupun diketahui oleh Osan. Walaupun Osan mengetahui perselingkuhan tersebut, ia tetap berbuat baik kepada Koharu, sehingga Koharu merasa malu. Dikarenakanbeberapa masalah dalam hubungan mereka, akhirnya Jihei dan Koharu pun memutuskan untuk melakukan shinju yang dilakukan di kuil Daichou.

Penelitian ini menggunakan penelitian mengenai shinju dari Ardhanariswari (2009) sebagai referensi. Artikel Ardhanariswari memberikan pemahaman mengenai faktor-faktor yang melatarbelakangi terjadinya shinju yang terjadi pada masyarakat Jepang. Selain itu, penelitian ini juga menggunakan penelitian mengenai fenomena jisatsu pada masa sebelum dan sesudah perang dunia II dari Adiningtyas(2008). Penelitian Adiningtyas memberikan pemahaman mengenai cara menganalisis menggunakan teori bunuh diri milik Emile Durkheim.

Adapun pokok permasalahan yang dibahas pada penelitian ini adalah sebagai berikut: Bagaimanakah faktor yang melatarbelakangi shinju dalam 
cerpen Sonezaki Shinju dan cerpen Shinju Ten no Amijima karya Chikamatsu Monzaemon?, Bagaimanakah pandangan pengarang mengenai shinju dalam cerpen Sonezaki Shinju dan cerpen Shinju Ten no Amijima karya Chikamatsu Monzaemon?

Adapun tujuan dari penelitian ini adalah untuk mengetahui faktor-faktor yang melatarbelakangi terjadinya shinju dan pandangan pengarang mengenai shinju dalam cerpen Sonezaki Shinju dan cerpen Shinju Ten no Amijima karya Chikamatsu Monzaemon (2007).

\section{METODE}

Penelitian ini dilakukan dengan metode kepustakaan dan teknik catat dalam pemerolehan data (Ratna, 2015:39), dianalisis dengan metode deskriptif analisis (Ratna, 2015:53), dan disajikan dalam metode informal (Ratna, 2015:50). Adapun teori yang digunakan dalam penelitian ini adalah teori sosiologi sastra oleh Wellek dan Warren (1990) sebagai acuan dasar dalam mengaitkan permasalahan sosial di masyarakat dan permasalahan sosial dalam karya sastra, teori bunuh diri oleh Emile Durkheim (1897) yang digunakan untuk menganalisi faktor-faktor yang melatarbelakangi terjadinya shinju, teori pandangan pengarang oleh Goldmann dalam Faruk (2010) yang digunakan untuk menganalisis pandangan pengarang terhadap shinju.

\section{HASIL DAN PEMBAHASAN}

Berikut merupakan penjabaran mengenai hasil analisis faktor-faktor yang melatarbelakangi terjadinya shinju.

Faktor yang Melatarbelakangi Shinju dalam Cerpen Sonezaki Shinju karya Chikamatsu Monzaemon

Pada penelitian ini ditemukan tiga faktor yang melatarbelakangi shinju dalam cerpen Sonezaki Shinju serta tiga faktor yang melatarbelakangi shinju dalam cerpen Shinju Ten no Amijima.

Faktor-faktor yang melatarbelakangi shinju di dalam kedua cerpen adalah sebagai berikut :

\section{a. Penolakan Atas Adat Perjodohan}

Pada cerpen Sonezaki Shinju karya Chikamatsu Monzaemon, perjodohan atau omiai kekkon menjadi salah satu faktor penyebab terjadinya shinju. Menurut Lebra dalam Mulyadi (2018:67) miai atau omiai kekkon adalah perjodohan atau perkawinan yang terjadi atas bantuan perantara yang mempertemukan kedua belah pihak calon pengantin. Tokoh Tokubei menolak perjodohan dengan keponakan dari istri pamannya karena telah memiliki kekasih yang bernama Ohatsu. Berikut adalah data-data yang menunjukkan mengenai penolakan terhadap adat perjodohan :

(1)「この正直を見てとって、おかみ さんの姪に二貫目の特参金を着け て夫婦にし、商売をさせようとい う相談が去年からあったが、お前 と言う恋人をもって、何の心が移 るものか」

（曽根崎心中、 2007 : 21 )

Kono shoujiki wo mitetotte, okamisan no mei ni nikanme no tokusankin wo tsukete fuufunishi, shoubai wo saseyou to iu soudan ga kyonen kara atta ga, omae to iu koibito wo motte, nan no kokoro ga utsuru monoka.

(Sonezaki Shinju, 2007:21)

'Setelah melihat kenyataan ini, uang yang diberikan istri pamanku memiliki tujuan khusus yaitu untuk menjodohkanku, lalu membicarakan mengenai bisnis serta menjalankan bisnis dari tahun lalu, mencarikanku 
kekasih, namun hati ini tidak akan berpindah'.

(Sonezaki Shinju, 2007:21)

Data (1) menunjukkan bahwa Tokubei mengatakan kepada Ohatsu bahwa ia dijodohkan oleh sang paman. Tokubei dijodohkan dengan keponakan dari istri pamannya. Perjodohan ini bertujuan agar kedepannya setelah menikah Tokubei bisa melanjutkan bisnis pamannya. Akan tetapi karena Tokubei telah memiliki kekasih yaitu Ohatsu, ia menolak perjodohan tersebut. Penolakan ini membuat sang paman marah. Paman dan istrinya berusaha menyuap ibu tiri Tokubei dengan memberikan sejumlah uang agar Tokubei mau menyetujui perjodohan tersebut. Namun Tokubei tetap menolak. Ini menunjukkan bahwa Tokubei menolak perjodohan tersebut hingga pada akhirnya membuatnya berpikir bahwa lebih baik ia melakukan shinju dengan Ohatsu daripada ia dijodohkan dengan wanita pilihan sang paman.

\section{b. Adanya Konflik On, Giri dan Ninjo}

Menurut Lebra (1976:195) on diartikan sebagai hutang budi, kewajiban atau kemurahan hati, sedangkan giri adalah suatu kewajiban moral yang dilakukan dengan "penuh keengganan" Benedict (1989:169). Giri akan muncul jika seseorang menerima on, yaitu utang yang harus dibayar kembali atau budi baik seseorang yang kita terima, sedangkan ninjo adalah suatu perasaan yang tidak menuntut balas, atau benarbenar tulus dari dalam hati dan tidak melibatkan hutang budi. Befu dalam Ariefa (2013:30) mengatakan bahwa berbeda dengan giri yang merupakan kewajiban moral untuk melakukan tindakan saling berbalasan, ninjo adalah kecenderungan, perasaan, dan keinginan alamiah manusia yang tidak terikat dengan norma-norma seperti halnya giri.
Pada cerpen Sonezaki Shinju karya Chikamatsu Monzaemon ini, tokoh Tokubei diceritakan telah menerima on dari sang paman dikarenakan ia telah dirawat dan diberikan pekerjaan oleh pamannya. Saat itu sang paman ingin menjodohkan Tokubei dengan keponakan dari istrinya dengan tujuan agar kedepannya Tokubei tetap bisa bekerja dengan pamannya dan meneruskan bisnis shouyu (kecap asin ala Jepang) sang paman. Akan tetapi, Tokubei menolak mentah-mentah perjodohan tersebut karena ia telah memiliki seorang kekasih yang bernama Ohatsu. Penolakan perjodohan itu menunjukkan bahwa ia tidak dapat membalaskan giri terhadap sang paman. Hal ini disebabkan karena Tokubei memiliki ninjo yaitu perasaan lebih mementingkan keinginan pribadi untuk tetap bersama kekasihnya dibandingkan dijodohkan oleh gadis pilihan pamannya. Oleh karena itu terjadilah konflik antara on yang telah diterima Tokubei, giri kepada sang paman dan ninjo dalam diri Tokubei sendiri. Konflik inilah yang menyebabkan Tokubei berpikir bahwa bunuh diri merupakan salah satu cara agar terlepas dari konflik on, giri dan ninjo tersebut.Berikut adalah data yang menunjukkan mengenai shinju sebagai jalan keluar dari konflik on, giri dan ninjo :

（2）分も男の意地。オオ、ソレ、承知

したと、田舎へ走つた。またこの

母という人が、この世があの世に

ひっくり返つても握つた銀を放し

はしない。京の五条の奨油問屋、

ふたん銀のやりとりをするので、

これを頼みに上京してみても、ち

ようど折悪く銀もない。引き返し 
て田舎へ行き、村中の人の頼みで 母から銀を受け取った。間もなく 返し、勘定もすませ、すっかり問 題は片がつく。

\section{（曽根崎心中、2 007 ：2 3)}

'Jibun mo otoko no iji. Oo, sore, shouchi shita to, inaka he hashitta. Mata kono haha to iu hito ga, kono yo ga ano yo ni hikkuri kaette mo nigitta kane wo hanashi wa shinai. Kyou no gojou no shouyu ton ya, futan kane no yaritori wo suru node, kore wo tanomi ni joukyou shitemitemo, choudo oriwaruku kane mo nai. Hikikaeshite inaka he iki, murajuu no hito no tanomi de haha kara kane wo uketotta. Mamonaku kaeshi, kanjou mo sumase, sukkari mondai ha katagatsuku'

(Sonezaki Shinju, 2007:23)

'Aku juga seorang pria. Oo, itu, ketika aku menyetujuinya, aku berlari ke desa. Ibu tiriku itu tidak akan mengembalikan uang tersebut meskipun dunia ini terbalik ke dunia yang lain. Karena berkewajiban mengembalikan uang yang telah diambil dari kedai kecap Gojou yang ada di Kyouto, meskipun pergi ke Tokyo untuk meminta bantuan, sayangnya uang pun tidak ada. Aku kembali ke desa dan meminta bantuan dari orang-orang di desa dan mendapatkan uang itu kembali dari ibu. Karena aku ingin mengembalikan uangnya sesegera mungkin, dan masalah pun selesai.'

$$
\text { 2007:23) }
$$$$
\text { (Sonezaki Shinju, }
$$

Data (2) menunjukkan dengan jelas sikap Tokubei yang lebih mementingkan ninjo dari pada giri. Ia bahkan tidak memperdulikan on yang telah diterimanya dari sang paman. Ia sangat menolak untuk dijodohkan, ia bahkan ia meminta tolong kepada orang-orang di desa untuk membantu merayu ibunya agar mau mengembalikan uang yang telah diberikan oleh pamannya. Hal tersebut dilakukan dengan tujuan untuk menolak perjodohan yang dilakukan oleh pamannya. Ia tak memperdulikan giri kepada pamannya walaupun dulu ia bekerja dan memiliki banyak hutang budi pada pamannya tersebut.

\section{c. Pembuktian Cinta}

Cerpen Sonezaki Shinju karya Chikamatsu Monzaemon menceritakan tokoh Tokubei yang menolak dijodohkan oleh pamannya dan memilih untuk bunuh diri bersama kekasihnya dengan harapan dapat bersama di kehidupansetelah mereka meninggal. Sakurai (1976:24) mengungkapkan pemikiran dalam agama Buddha percaya dengan adanya reinkarnasi, dimana jika tidak ada harapan untuk bersama pada kehidupan yang sekarang, maka kebahagiaan dapat diperoleh di kehidupan yang akan mendatang. Kepercayaan ini jugayang membuat tokoh Tokubei memutuskan untuk melakukan shinju bersama kekasihnya. Tak hanya Tokubei, Ohatsu juga bersedia melakukan shinju karena rasa cintanya pada sang kekasih. Berikut adalah data yang menunjukkan mengenai shinju sebagai bentuk dari pembuktian cinta.

(3)「いつまでもわれとお前は夫 婦星、かならず添おう」

\section{（曽根崎心中、2 007 ：3 3 ）}

"Itsumade mo ware to omae wa meotoboshi, kanarazu soou" (Sonezaki Shinju, 2007:33) 
"Sampai kapanpun aku dan kamu akan selalu saling menemani seperti bintang yang berpasangan" (Sonezaki Shinju, 2007:33)

Data (3) atas menunjukkan bahwa betapa besarnya cinta mereka satu sama lain, terlebih cinta Tokubei pada Ohatsu. Ia percaya bahwa kalaupun mereka akan melakukan shinju nanti, mereka akan tetap saling menemani layaknya bintang yang berpasangan. Ungkapan meotoboshi pada kalimat tersebut mengasumsikan makna sepasang kekasih yang akan selalu bersama dan tak dapat terpisahkan oleh kematian.Pada akhirnya mereka berdua mengakhiri hidup dengan cara melakukan shinju di hutan Sonezaki.

Faktor yang Melatarbelakangi Shinju dalam Cerpen Sonezaki Shinju karya Chikamatsu Monzaemon

Pada bagian ini dijelaskan mengenai faktor-faktor yang melatarbelakangi terjadinya shinju dalam cerpen Shinju Ten no Amijima karya Chikamatsu Monzaemon. Deskripsi penjelasan dari faktor-faktor tersebutdijelaskan secara berkesinambungan sesuai dengan data yang terdapat pada objek kajian. Berikut adalah data-data tersebut :

\section{a. Pelaksanaan Giri}

Koharu seorang wanita penghibur berselingkuh dengan Jihei yang tak lain adalah suami sahabatnya sendiri. Ia merasa sangat malu dan merasa bahwa dirinya sangatlah jahat karena telah menghianati sahabatnya, Osan. Maka dari itu, Koharu berpikir bahwa dengan melakukan shinju maka ia akan melaksanakan giri kepada Osan. Hal tersebut dapat dilihat pada data berikut :

(4)「さっぱりと死ぬに場所も変え、 山と川に別れよう。この水門の上を 山になぞらえ、お前の最期場とし、
わたしはまだこの流れのところで首 をくくり、最期は同じ時ではあって

も、命を捨てる手段も場所も変えて、 おさんに立て通す義理を示そう。

\section{（死中天の網島、2007：122）}

"Sappari to shinu ni basho mo kae, yama to kawa ni wakareyou. Kono suimon no ue o yama ni nazorae, omae no saigo-ba to shi, watashi wa mada kono nagare no tokoro de kubi o kukuri, saigo wa onaji toki de wa atte mo, inochiwosuteru shudan mo basho mo kaete, Osan ni tatetousu giri o shimesou."

(Shinju Ten no Amijima, 2007:122)

"Ubah tempat pilihan kita untuk mati bersama, kita membagi diri antara gunung dan sungai. Gunung yang ada di atas bendungan ini akan menjadi tempat terakhirmu dan aku akan mengikat diriku agar tidak hanyut dalam arus sungai ini, walau nanti akhirnya kita melepas nyawa bersama, kita ubah cara dan tempat untuk melepas kehidupan ini, lalu tunjukkan kepada Osan bahwa inilah giri kita."

(Shinju Ten no Amijima, 2007:122)

Data (4) menunjukkan bahwa Koharu dan Jihei merencanakan dimana dan bagaimana mereka akan melakukan shinju. Dapat dilihat pada kalimat Osan ni tatetousu giri o shimesou" yang berarti "kita tunjukkan kepada Osan bahwa inilah giri kita" sudah sangat jelas menunjukkan bahwa mereka benar-benar ingin mengakhiri hidup mereka dengan cara melakukan shinju sebagai bentuk dari pelaksanaan giri. Jadi dapat disimpulkan bahwa salah satu faktor terjadinya fenomena shinju dalam cerpen Shinju Ten no Amijima karya Chikamatsu 
Monzaemon adalah sebagai pelaksanaan giri.

b. Bentuk dari Rasa Malu

Benedict (1989:105) menjelaskan bahwa rasa malu muncul dikarenakan ketidakmampuan membalas budi dari orang lain. Kustianty dalam Rahman (2012:117) mengatakan bahwa konsep haji atau rasa malu ini berkaitan dengan kehidupan masyarakat dan kelompok, atau individu dan individu lainnya. Pada cerpen Shinju Ten no Amijima karya Chikamatsu Monzaemon menceritakan bahwa perasaan malu menjadi salah satu faktor terjadinya shinju. Koharu yang merasa sangat malu karena telah merebut Jihei, suami dari Osan yang tak lain adalah sahabatnya sendiri. Ia semakin merasa malu karena walaupunOsan telah mengetahui perselingkuhannya dengan Jihei, namun Osan tetap membantunya dan merelakan Jihei untuknya. Berikut adalah data-data yang menunjukkan mengenai shinju sebagai bentuk rasa malu dalam cerpen Shinju Ten no Amijima karya Chikamatsu Monzaemon :

(5) 取り交わしたその手紙の約束を 無にして、大切な男をそそのか しての心中は、やはりその場か ぎりの遊女、義理知らず、偽り ものとおさん様から思われるで しょう」。

(死中天の網島、2007：1 2 2)

"Torikawashita sono tegami no yakusoku o mu ni shite, taisetsuna otoko o sosonokashite no shinjū wa, yahari sono ba kagiri no yüjo, girishirazu, itsuwari mono to Osansama kara omowarerudesho". (Shinju Ten no Amijima, 2007:122)
"Perjanjian yang sudah disepakati di dalam surat itu pun tidak dipedulikannya, sampai-sampai kau merebut serta mengajak untuk bunuh diri bersama, sudah aku duga ternyata benar kau itu hanya wanita yang seperti itu, wanita yang tidak tahu balas budi. Pastinya Osan akan berfikir kau adalah wanita yang penuh dengan kebohongan."

(Shinju Ten no Amijima, 2007:122)

Data (5) di atas menceritakan katakata dalam hati Koharu yang secara tidak langsung menjelekkan dirinya sendiri. Ia merasa malu terhadap sahabatnya yang tak lain adalah istri dari Jihei yaitu Osan. Koharu merasa bahwa dirinya benarbenar wanita yang jahat, dirinya bahkan sampai akan melakukan shinju bersama suami sahabatnya sendiri. Koharu merasa bahwa ia adalah orang yang tidak tahu balas budi. Dari kalimat yang di utarakan oleh Koharu sangat jelas memperlihatkan bahwa iamerasa sangat malu kepada Osan. Setelah berkelut dengan kata hatinya sendiri, Koharu mengutarakan rasa malu di dalam hatinya kepada Jihei sesaat sebelum mereka melakukan shinju.

\section{Pandangan Dunia Pengarang Terhadap Shinju dalam Cerpen Sonezaki Shinju dan Cerpen Shinju Ten no Amijima karya Chikamatsu Monzaemon}

Berikut akan dianalisis mengenai pandangan dunia pengarang yang terdapat dalam cerpen Sonezaki Shinju dan cerpen Shinju Ten no Amijima karya Chikamatsu Monzaemon.

a. Shinju Bertujuan untuk Memulihkan Harga Diri 'Jichou'

Pada cerpen karyanya yang berjudul Sonezaki Shinju ditemukan data mengenai pandangan Chikamatsu Monzaemon tentang shinju sebagai suatu cara untuk memulihkan kembali harga 
diri dengan cara melakukan bunuh diri bersama. Berikut adalah data-data tersebut :

(6) 無念だ。このように踏みたたかれ、 男も立たない、身も立たない。 エ工最前につかみつき、食らいつ いてでも死にたかつた。

（曽根崎心中、 2007 ：26）

"Munenda. Ko no you ni fumi tatakare, otoko mo tatanai, mi mo tatanai. Ee saizen ni tsukami tsuki, kuraitsuite demo shinitakatta."

(Sonezaki Shinju, 2017:26)

"Tak tau harus bagaimana lagi. Sudah di perlakukan seperti ini, harga diriku sebagai laki-laki pun telah jatuh, raga ini sudah tidak kuat lagi. Ee aku ingin menggengam erat hal yang penting, dan ingin mengakhiri hidupku."

(Sonezaki Shinju, 2017:26)

Data (6) menunjukkan sikap Tokubei yang merasa kehilangan harga dirinya dan ingin mengakhiri hidupnya karena merasa kehormatannya telah hilang. Chikamatsu berpandangan bahwa tokoh Tokubei dalam cerita Sonezaki Shinju yang ditulisnya melakukan shinju untuk memulihkan martabat, harga diri dan kehormatannya. Ia mengisahkan tokoh Tokubei yang sudah berbaik hati pada sahabatnya yaitu Kuheiji dengan meminjamkan uang yang seharusnya ia kembalikan pada pamannya. Kuheiji berjanji akan mengembalikan uang itu, namun saat menagih uang tersebut ternyata yang Tokubei dapat hanyalah penghinaan. Kuheiji pun menuduh Tokubei telah merampas semua hartanya sehingga membuat teman-temannya menghajar Tokubei. Ini membuat Tokubei merasa harga dirinya telah diinjak-injak. Ia juga merasa sangat bersalah karena tidak bisa mengembalikan uang itu pada sang paman. Ia pun bertekad untuk melakukan shinju sebagai bentuk untuk memulihkan harga dirinya. Rahmah (2018:5) mengatakan bahwa seorang samurai memiliki harga diri yang sangat tinggi yang benar-benar dijaga dengan cara berperilaku terhormat. Latar belakang Chikamatsu yang merupakan anak dari keluarga samurai inilah yang membuatnya memiliki pandangan tersendiri tentang shinju.

\section{SIMPULAN}

Berdasarkan hasil penelitian pada kedua cerpen karya Chikamatsu Monzaemon ditemukan tiga faktor penyebab terjadinya shinju dalam cerpen Sonezaki Shinju. Yang pertama yaitu penolakan terhadap adat perjodohan. Pada zaman Edo masyarakat Jepang menganut adat perjodohan atau dalam bahasa jepang disebut 'omiai kekkon' demi melanjutkan bisnis atau usaha sebuah keluarga. Tokoh Tokubei dalam cerpen ini menolak perjodohan tersebut sehingga berujung melakukan shinju karena ia tak mau dijodohkan. Yang kedua adanya konflik on, giri, dan ninjo. . Konsep on, giri, dan ninjo yang sangat kental dalam masyarakat Jepang juga menjadi salah satu penyebab terjadinya shinju, ketika seseorang tidak dapat menyeimbangkannya maka konflik antara on, giri, dan ninjo pun akan terjadi dan menimbulkan dampak seperti shinju. Faktor terakhir adalah pembuktian cinta, dimana dalam agama Buddha mempercayai jika tidak mendapat kebahagiaan di kehidupan saat ini maka kelak akan mendapat kebahagiaan dan dapat bersatu di kehidupan selanjutnya. Dalam cerpen kedua yaitu Shinju Ten no Amijima terdapat tiga faktor yang melatar belakangi yaitu shinju sebagai 
pelaksanaan giri, bentuk dari rasa malu dan pembuktian cinta.

Chikamatsu Monzaemon selaku pengarang kedua cerpen ini memiliki pandangan terhadap shinju itu sendiri. Latar belakang Chikamatsu yang merupakan keluarga seorang samurai membuat dirinya memiliki pemikiran bahwa dengan melakukan bunuh diri dapat menjadi bentuk memulihkan harga diri dan juga untuk penghapusan rasa malu. Hal ini adalah contoh dari fakta individual yang ada dalam diri Chikamatsu. Tak hanya itu, fakta sosial berupa pandangan masyarakat Jepang tentang samurai dan bunuh diri pun sama. Menurut masyarakat Jepang bunuh diri tidak selalu dianggap sebagai ekspresi kesengsaraan hidup, tetapi dalam beberapa kasus tertentu, bunuh diri juga dipandang sebagai ekspresi dari penilaian kematian sebagai pilihan yang anggun dan terhormat. Hal tersebutlah yang membuat Chikamatsu menulis beberapa kisah tentang shinju.

\section{REFERENSI}

Adiningtyas, 2008.Fenomena Jisatsu pada Masa Sebelum dan Sesudah Perang Dunia II: sebagai Tinjauan Struktur Keluarga (skripsi). Depok: Universitas Indonesia.

Ardhanariswari, 2009. Latar Belakang Shinju Tokoh Kuki dan Rinko dalam Novel Shitsurakuen (skripsi). Depok: Universitas Indonesia.

Ariefa, Nina Alia. 2013. Tema dan Nilai Kehidupan dalam Lakon Sugawara Denju Tenarai Kagami. Dalam Jurnal Al-Azhar Indonesia Seri Humaniora, Volume 2, Nomor 1, hlm. 21-32. Jakarta: Universitas AlAzhar Indonesia.
Benedict, Ruth. 1989. Pedang Samurai dan Bunga Seruni (The Chrysantheum and The Sword), Alih Bahasa, Pramudji. Jakarta: Sinar Harapan.

Durkheim, Emile. 1897. Suicide:A Study of Sociology. London: Routledge Classics.

Eisenstadt, S.N. 1996. Japanese Civilization : A Comparative View. Chicago, IL : University of Chicago.

Faruk. 2010. Pengantar Sosiologi Sastra. Yogyakarta: Pustaka Pelajar.

Lebra, Takie Sugiyama. 1976, Japanese Patterms of Behavior. Hawaii: The University Press of Hawaii.

Monzaemon, Chikamatsu dan Haruo, Suwa. 2007. Sonezaki Shinju Shinju Ten no Amijima Gendai Goyakutsuki. Tokyo: Kadokawa.

Mulyadi, Budi. 2018. Fenomena Penurunan Angka Pernikahan dan Perkembangan Budaya Omiai di Jepang. Dalam Kiryoku. Volume 2, Nomor 2, hlm. 65-71. Semarang: Universitas Diponegoro.

Rahman, Aditia. 2012. Korelasi Konsep Haji dalam Peristiwa Pengunduran Diri Pejabat Pemerintah Jepang. Dalam Japanology, Volume 1, Nomor 1, hlm. 116-126. Surabaya: Universitas Airlangga.

Rahmah, Yuliani. 2018. Nilai-Nilai Bushido dalam Minwa. Dalam Kiryoku. Volume 2, Nomor 1, hlm. 1-10. Semarang: Universitas Diponegoro. 
Ratna, Nyoman Kutha. 2015. Teori, Metode, dan Teknik Penelitian Sastra. Yogyakarta: Pustaka Pelajar.

Sakurai, Tokutaro. 1976. Nihon Minzokugaku Koza. Japan : Charles E Tuttle

Wellek, Renne dan Austin Warren. 1990. Teori Kesusastraan (Diterjemahkan Oleh Melani Budianta). Jakarta: Pustaka Jaya. 